1990s alone, including his work with the landmark Direct Observation of Primary Care Study. He credited much of his research division's productivity to ongoing work with the practice-based research network founded by Kurt Stange, MD, in 1994. "Right from the start, we took a transdisciplinary, multimethod approach," Dr. Zyzanski said. "We routinely integrate qualitative and quantitative methods, and we found that simultaneous use of these methods has yielded a much larger collection of findings without undue added effort." He reviewed some key findings from some of the network's studies, including measurement of preventive service delivery, the effect of patient volume on a practice, the incorporation of family in family medicine, and a tailored approach to improving preventive service delivery in primary care practice. Dr. Zyzanski acknowledged his professional relationships with Dr. Stange and Jack Medalie, MD, and his collaborative work with Ben Crabtree, MD, and Will Miller, MD, as key ingredients to his success in research.

An exciting project that has consumed much of Dr. Zyzanski's energy has been the development of an electronic database of more than 400 behavioral measures useful in primary care research. He is particularly proud of this collection, considering that he started his career trying to establish the validity of behavioral risk factors. This resource will be available on the Internet later this year. Dr. Zyzanski has also devoted much of his time lately to his role as statistical editor of the Annals of Family Medicine. In this context, he discussed effect size and clustered data, 2 topics generating a large amount of interest lately in statistics, medicine, and behavioral science. "More journals are now requiring that authors provide statistical tests of hypotheses, they also provide a measure of effect size," he said. Regarding clustered data, which are present in practice-based research network studies "almost by design," Dr. Zyzanski recommended increasing familiarity with techniques that adjust for the clustering effect.

Dr. Zyzanski concluded his presentation by distilling his experience into the essential ingredients for successful research: passion, research training, mentors, and a multidisciplinary collaborative research team. For his remarkable lifetime of dedication to family medicine research and his ongoing commitment to strengthening the science of our field, the Hames Selection Committee is honored to present the 2004 Curtis G. Hames Research Award to Dr. Stephen Zyzanski.

Erik Lindbloom, MD, MSPH Chair, STFM Researcb Committee and Hames Selection Committee

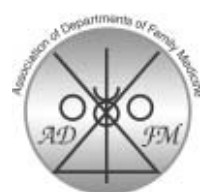

From the Association

of Departments of Family Medicine

Ann Fam Med 2004;2:374-375. DOI: 10.1370/afm.211.

\section{FAMILY MEDICINE AND ACADEMIC HEALTH CENTERS}

The Future of Family Medicine Project has elicited quite a bit of reaction within academic departments. While most of the reaction has been quite positive, there has been spirited disagreement with the section on the role of family medicine in academic health centers. In the update below, Mike Magill shares his concerns with the recommendation and offers a different perspective. The Association of Departments of Family Medicine will be working with all family medicine chairs to develop individual institutional responses to the report, while sharing the range of views about this recommendation with the wider family.

Lloyd Michener

Duke University

\section{A Different Perspective}

The Future of Family Medicine Project (FFM) represents a critical step toward revitalization of our specialty. The FFM project report also reflects, however, an outdated and potentially self-limiting view of family medicine in academic health centers (AHCs).

Recommendation 7 of the report says:

"Departments of family medicine will individually and collectively analyze their position within the academic health center setting and will take steps to enhance their contribution to the advancement and rejuvenation of the academic health center to meet the needs of the American people. A summit of policy makers and family medicine leaders in academia and private practice will be convened to review the role of and make recommendations on the future of family medicine in academia."

The tentativeness of recommendation 7 stands in contrast to the bold, concrete language of the other recommendations of the report, which articulate a sharp vision of a reinvigorated discipline that sets a standard for American medicine. Recommendation 7 is timid by contrast. The related report of FFM Task Force 5 focuses on leadership by family physicians to transform the health care system. But even here, the ambivalence of family medicine toward AHCs is evident when the report says, "while some may debate whether medical schools and academic medical centers 
are change agents, they do have influence and must be addressed." $^{\prime 2}$

Family medicine has a history of uncomfortable relationships with AHCs. Many, but not all, AHCs vigorously resisted development of our specialty. A few, demonstrating a remarkable capacity for denial of reality, still do. Some AHCs actively obstruct needed reform of American health care. As one who has spent substantial portions of my career both in and out of AHCs, I have seen all of this and more firsthand. I am intimately familiar with the many challenges AHCs pose for our specialty.

Nonetheless, I believe AHCs need courageous leadership from family medicine. AHCs exert extraordinary influence on the shape of American health care through their pivotal roles in research, education, and patient care. No lasting transformation of American health care will occur without AHC participation, if not leadership. As Barbara Starfield said in her e-letter to the Annals of Family Medicine, the FFM report "is bold but not brave.... A brave stance regarding the role of family medicine requires confronting ... the iron grip that specialist and academic health centers have on health policy decisions." ${ }^{13}$

$\mathrm{AHCs}$ are also under tremendous stress and in need of change themselves. Fortunately, many family physicians are already changing AHCs across the country as department chairs, associate deans, medical directors, AHEC directors, course directors, research center directors, and deans. They are creating innovative programs that help patients and communities while demonstrating importance of family medicine to AHCs, not because of mandates from policy makers, but because family physicians deliver real value tested in the harsh and competitive world of the AHC. Family physicians are leading AHCs to develop new models of care and to create climates of excitement and rigor to invigorate our students, residents, and practicing family physicians.

The position of family medicine in AHCs has grown enormously in the last 30 years. Family medicine's AHC "glass" may be less than completely full, but it is definitely not as empty as when our discipline was founded. It is time for us to drop our sense of being downtrodden, misunderstood, unloved. If we are frustrated with our role in AHCs today, it may more because of self-defined limitations than lack of actual success or opportunity for further influence.

We should acknowledge our past and move on. Family physicians in AHCs need the support of the entire specialty as we challenge conventional wisdom, both our own and the AHCs'. Chairs of medical school departments of family medicine are major leaders of our discipline in AHCs and compose the membership of ADFM. ADFM should accept a leadership role for efforts by family medicine to help transform AHCs.

I would suggest as an alternative to FFM Recommendation 7 :

"Family physicians will lead transformation of AHCs to better meet the health care needs of the American people by driving reform in AHCs' clinical care to establish excellence in service, outcomes, safety, and improved health of communities; implementing research and health system development to achieve these goals; creating programs to help practicing family physicians implement the New Model of family medicine; and educating health care professionals to succeed in the reformed health care system of the future. ADFM will convene leadership of family medicine and AHCs to disseminate examples of successful family medicine leadership in AHCs and to implement sustained change in AHCs that will benefit family medicine, AHCs, and the health of the American people."

Michael K. Magill, MD

Professor and Chairman

Department of Family and Preventive Medicine University of Utab School of Medicine

\section{References}

1. Future of Family Medicine Project Leadership Committee. The future of family medicine: a collaborative project of the family medicine community [online]. Available at: http://www.annfammed.org/cgi/ reprint/2/suppl_1/s3.

2. Roberts RG, Snape PS, Burke K, for the Task Force 5 Writing Group. Task Force Report 5: report of the task force on family medicine's role in shaping the future health care delivery system. Available at: http://www.annfammed.org/cgi/reprint/2/suppl_1/s88.

3. Starfield B. Whither family medicine [eletter]. http://www. annfammed.org/cgi/eletters/2/suppl_1/s3\#483, April 6, 2004.

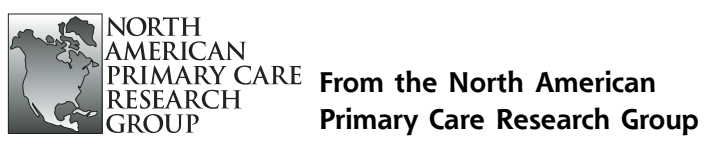

Ann Fam Med 2004;2:375-376. DOI: 10.1370/afm.212.

\section{FREQUENTLY ASKED QUESTIONS ABOUT FAMILY MEDICINE RESEARCH FOR MEDICAL STUDENTS AND RESIDENTS}

The Future of Family Medicine report emphasizes the importance of research to all family physicians and the need to expose students and residents to research experiences in family medicine. The North American Primary Care Research Group (NAPCRG) is pleased to offer the following Frequently Asked Questions About Family Medicine Research for Medical Students and Residents as a tool to help introduce the next generation of family physicians to the vital role of primary 